\title{
Treatment of ruptured complex and large/giant ruptured cerebral aneurysms by acute coiling followed by staged flow diversion
}

\author{
Waleed Brinjikji, MD, ${ }^{1}$ Mariangela Piano, MD, ${ }^{4}$ Shanna Fang, MD, ${ }^{2}$ Guglielmo Pero, MD, ${ }^{4}$ \\ David F. Kallmes, MD, ${ }^{1,3}$ Luca Quilici, MD, ${ }^{4}$ Luca Valvassori, MD, ${ }^{4}$ Emilio Lozupone, MD, ${ }^{5}$ \\ Harry J. Cloft, MD, PhD, ${ }^{13}$ Edoardo Boccardi, MD, ${ }^{4}$ and Giuseppe Lanzino, MD ${ }^{1,3}$

\begin{abstract}
${ }^{1}$ Departments of ${ }^{1}$ Radiology and ${ }^{3}$ Neurologic Surgery and ${ }^{2}$ Mayo Medical School, Mayo Clinic, Rochester, Minnesota, Mayo Clinic, Rochester, Minnesota; ${ }^{4}$ Department of Radiology, Hospital Niguarda, Milan; and ${ }^{5}$ Department of Radiodiagnostics, Gemelli Hospital, Rome, Italy
\end{abstract}

\begin{abstract}
OBJECTIVE Flow-diversion treatment has been shown to be associated with high rates of angiographic obliteration; however, the treatment is relatively contraindicated in the acute phase following subarachnoid hemorrhage (SAH) as these patients require periprocedural dual antiplatelet therapy. Acute coiling followed by flow diversion has emerged as an intriguing and feasible treatment option for ruptured complex and giant aneurysms. In this study the authors report outcomes and complications of patients with ruptured aneurysms undergoing coiling in the acute phase followed by planned delayed flow diversion.
\end{abstract}

METHODS This case series includes patients from 2 institutions. All patients underwent standard endovascular coiling in the acute phase after SAH with the intention and plan to proceed with flow diversion at a later date. Outcomes studied included angiographic occlusion, procedure-related complications, and long-term clinical outcome as measured using the modified Rankin Scale.

RESULTS A total of 31 patients underwent coiling in the acute phase with the intention to undergo flow diversion at a later date. The mean aneurysm size was $15.8 \pm 7.9 \mathrm{~mm}$. Of the 31 patients undergoing coiling, 4 patients could not undergo further flow-diverter therapy: 3 patients (9.7\%) died of complications of subarachnoid hemorrhage and 1 patient had permanent morbidity as a result of perioperative ischemic stroke (3.1\%). Twenty-seven patients underwent staged placement of flow diverters after adequate recovery. The median time to treatment was 16 weeks. There was one case of aneurysm rebleeding following coil treatment. There were no cases of permanent morbidity or mortality resulting from flow-diverter treatment. Twenty-four patients underwent imaging follow-up; 18 of these patients had aneurysms that were completely or nearly completely occluded (58.1\% on an intent-to-treat basis). At last follow-up (mean 18.3 months), 25 patients had mRS scores $\leq 2$ (80.6\% on an intent-to-treat basis).

CONCLUSIONS Staged treatment of ruptured complex and giant intracranial aneurysms with coiling in the acute phase and flow-diverter treatment following recovery from SAH is both safe and effective. In this series, no cases of rebleeding occurred during the interval between coiling and flow diversion. This strategy should be considered as a valid option in patients presenting with these challenging ruptured aneurysms.

http://thejns.org/doi/abs/10.3171/2015.6.JNS151038

KEY WORDS flow diverter; coil; aneurysm; vascular disorders

$\mathrm{E}$ NDOVASCULAR coiling and surgical clipping are the 2 primary treatment modalities for treating acutely ruptured intracranial aneurysms; however, each of these treatment modalities has limitations. ${ }^{7,10}$ Surgical clipping in the acute phase is complicated by the presence of subarachnoid blood and brain edema, which make dis- section and exposure of the aneurysm difficult. In the case of ruptured complex and giant aneurysms, the need for prolonged temporary clipping further increases the risk of the procedure. Subarachnoid blood and cerebral edema do not affect the technical aspects of endovascular coiling. However, in the case of acutely ruptured complex and gi-

ABBREVIATIONS ICA = internal carotid artery; $m R S=$ modified Rankin Scale; $P E D=$ Pipeline Embolization Device; SAH = subarachnoid hemorrhage; WFNS = World Federation of Neurosurgical Societies.

SUBMITTED May 5, 2015. ACCEPTED June 30, 2015.

INCLUDE WHEN CITING Published online December 11, 2015; DOI: 10.3171/2015.6.JNS151038. 
ant aneurysms, coiling is associated with less than ideal long-term obliteration rates. ${ }^{3,8,14}$

Recently, flow diversion has emerged as an excellent treatment option for unruptured and previously coiled aneurysms due to its high complete angiographic occlusion rates even in the case of large and giant proximal intracranial internal carotid artery (ICA) aneurysms. ${ }^{6}$ Yet, application of flow diversion in the setting of acute aneurysm rupture is limited by the need for dual antiplatelet therapy and the risk of aneurysm rupture as the treatment works progressively over time in closing the aneurysm.

One potential treatment paradigm that has not been extensively explored is the role of planned staged endovascular treatment with coiling in the acute phase to reduce early rebleeding risk followed by planned flow diversion once the patient is stabilized and able to tolerate dual antiplatelet therapy. We report a consecutive series of patients from 2 institutions with acutely ruptured large and/or complex aneurysms treated with a staged approach of conventional coiling followed by flow diversion after the patient has recovered from the acute effects of subarachnoid hemorrhage (SAH).

\section{Methods \\ Institutional Experience}

This prospective case series included patients from 2 institutions with a tertiary cerebrovascular center: Mayo Clinic, Rochester, Minnesota, and Ospedale Niguarda, Milano, Italy. Approval from the institutional review board at each institution was obtained for review of prospectively maintained databases of all patients between April 2009 and August 2014 who underwent coil embolization with the intention of subsequent flow-diversion therapy for treatment of ruptured intracranial aneurysms. All patients provided consent allowing use of their medical records for research purposes. All patients were informed of the plan to perform staged coil embolization followed by flowdiverter treatment for their complex ruptured intracranial aneurysm. Patients were considered for surgical clipping, but clipping was not performed because of aneurysm location, complexity, or patient preference. Demographic characteristics, clinical presentation (including Hunt and Hess score, Fisher grade, and World Federation of Neurosurgical Societies [WFNS] subarachnoid hemorrhage grade), aneurysm size (maximum diameter measured by 3D digital subtraction angiography), and aneurysm location were recorded for each patient.

\section{Endovascular Technique}

All patients underwent standard endovascular coiling in the acute phase after SAH. The intention was not to achieve complete occlusion during the first part of this staged treatment. Flow diversion was scheduled and considered after a variable period of time (and usually during a separate hospitalization) once patients were considered to have recovered from the acute phase following SAH. Prior to subsequent flow diversion, patients were medicated with aspirin and clopidogrel and maintained with full anticoagulation during the procedure. No patient underwent testing for platelet responsiveness to clopidogrel or aspirin. After the procedure, patients continued dual antiplatelet therapy for a minimum of 3 months based on individual patient and aneurysm characteristics. The number and sizes of flow diverters chosen in each case were based on the diameter of the parent vessel and ability for adequate coverage of the aneurysm neck. All endovascular procedures were performed with patients under general anesthesia. 3D digital subtraction angiography images of the entire circulation were obtained at 2 frames per second before and after placement of the coils or flow diverters. For every endovascular procedure, data were collected regarding use of adjunctive devices, type of flow diverter used, intraprocedural complications, and immediate angiographic occlusion status.

\section{Angiographic and Clinical Outcomes}

Angiographic outcomes for coiling and flow diversion were stratified into 3 categories based on degree of aneurysm occlusion. 1) Complete occlusion was defined as absence of angiographic filling in the aneurysm neck or sac. 2) Near-complete occlusion was defined as small residual neck filling without any filling of the aneurysm sac. 3) Partial occlusion was defined as persistent filling of the aneurysm sac and neck. For coil embolization, the angiographic status of the aneurysm was determined by the surgeon immediately after coiling and prior to the staged flow-diversion procedure. After placement of the flow diverter, the extent of angiographic obliteration was assessed at the last follow-up. Aneurysm rupture or ischemic/thromboembolic complications were categorized as procedure related, while other clinical complications were categorized as SAH related if the clinical outcome was not related to the endovascular procedure and occurred during the acute phase of the SAH. Periprocedural complications were further stratified into early complications ( $\leq 30$ days) or late complications (> 30 days). The modified Rankin Scale (mRS) was retrospectively used to describe the extent of patient disability at time of discharge from procedures and at the last clinical follow-up visit.

\section{Statistical Analysis}

No statistical comparisons were made in this study. All continuous variables are presented as the mean \pm SD . All categorical variables are presented with their corresponding percentages. Analyses of final clinical and angiographic outcomes were performed on an intent-to-treat basis. All analyses were performed using the SAS-based statistical software package JMP version 10.0 (www.jmp. com).

\section{Results \\ Patient Characteristics}

A total of 31 patients (17 females and 14 males) underwent coiling in the acute phase with the intention to consider flow diversion at a later time. Twenty-nine of these patients experienced rupture of previously untreated aneurysms, and 2 patients had rupture of previously coiled aneurysms.

The mean age at the time of SAH was $52.1 \pm 11.1$ years (range 30-72 years). On presentation, the Hunt and Hess grade was I in 14 patients (45.2\%), II in 6 patients (19.4\%), 
III in 4 patients (12.9\%), IV in 1 patient (3.2\%), and V in 6 patients (19.4\%). The mean maximum diameter of these aneurysms was $15.8 \pm 7.9 \mathrm{~mm}$. Aneurysms were located in the supraclinoid ICA in 12 patients, ICA terminus in 6 patients, anterior communicating artery in 5 patients, and basilar bifurcation in 4 patients. Eleven of 31 patients (35.5\%) had additional aneurysms. Demographic information, clinical presentation, and aneurysm characteristics are summarized in Table 1.

\section{Endovascular Coiling Perioperative Outcomes}

Endovascular coiling outcomes are summarized in Table 2. During the initial coiling procedure, all aneurysms were successfully treated without the use of stent assistance; 1 case (3.2\%) required the use of balloon assistance. The intention in most instances was not to achieve complete occlusion during the first part of this staged treatment but to provide short-term protection from rebleeding. Angiographic occlusion immediately after coiling showed complete occlusion in 3 cases (9.7\%), near-complete occlusion in 13 cases (41.9\%), and incomplete occlusion in 15 cases $(48.4 \%)$. There were 2 cases $(6.5 \%)$ of intraoperative rupture with no associated permanent morbidity or mortality. Two patients had groin hematomas postprocedure.

During the course of their hospitalization, $45.2 \%$ of patients developed symptomatic hydrocephalus as a result of their $\mathrm{SAH}$, requiring transient management with lumbar drains or placement of external ventricular drains. Vasospasm was medically treated in 9 patients (29\%), and 5 vasospasm patients $(16.1 \%)$ were treated with endovascular intervention (2 with intraarterial verapamil infusion and 3 with angioplasty). During the initial coiling phase, there were 4 cases of perioperative ischemic stroke leading to permanent morbidity in 2 cases. One of these patients suffered a carotid occlusion due to thrombosis adjacent to his coiled right ICA aneurysm 4 days after treatment and had subsequent widespread vasospasm related to the subarachnoid hemorrhage that led to right middle cerebral artery and anterior cerebral artery distribution infarcts despite a decompressive hemicraniectomy and 2 subsequent intraarterial verapamil infusions.

There was 1 case of early rebleeding following the coiling stage of the planned staged treatment. A 35-year-old female patient with a $20-\mathrm{mm}$ ophthalmic ICA aneurysm had rupture of the target aneurysm within 30 days of treatment. The patient did not experience any additional morbidity from the rebleeding. She underwent re-coiling with the intent to perform flow diversion within 16 weeks. At final clinical follow-up, this patient had an mRS score of 4. Another patient underwent planned staged coil-flow diverter treatment of a previously coiled ruptured aneurysm. This patient was a 72-year-old woman with an 11$\mathrm{mm}$ supraclinoid ICA aneurysm that reruptured 9 months after coil embolization. In this case, initial coil treatment was not performed as part of the staged coil-flow diversion protocol. However, the decision was made by the practitioners to re-treat the aneurysm with coiling in the acute phase followed by flow-diverter treatment within 16 weeks. At final clinical follow-up, this patient had an $\mathrm{mRS}$ score of 3.

At the time of initial discharge, $32.3 \%$ of patients had no symptoms (mRS Score 0 ), $16.1 \%$ of patients had mi-
TABLE 1. Patient and aneurysm characteristics

\begin{tabular}{|c|c|}
\hline Variable & Value ${ }^{*}$ \\
\hline No. of patients & 31 \\
\hline Female/male & $17(55) / 14(45)$ \\
\hline \multicolumn{2}{|l|}{ Age at SAH in yrs } \\
\hline Mean \pm SD & $52.1 \pm 11.1$ \\
\hline Range & $30-72$ \\
\hline Cranial nerve deficit at presentation & $11(35)$ \\
\hline \multicolumn{2}{|l|}{ GCS score at admission } \\
\hline 3 & $3(9.7)$ \\
\hline 6 & $2(6.5)$ \\
\hline 7 & $1(3.2)$ \\
\hline 8 & $1(3.2)$ \\
\hline 11 & $1(3.2)$ \\
\hline 12 & $1(3.2)$ \\
\hline 13 & $4(12.9)$ \\
\hline \multicolumn{2}{|l|}{ WFNS grade } \\
\hline V & $6(19.4)$ \\
\hline IV & $3(9.7)$ \\
\hline III & $1(3.2)$ \\
\hline II & $8(25.8)$ \\
\hline I & $13(41.9)$ \\
\hline \multicolumn{2}{|l|}{ Fisher grade } \\
\hline 1 & $3(9.7)$ \\
\hline 2 & $3(9.7)$ \\
\hline 3 & $9(29.0)$ \\
\hline 4 & $16(51.6)$ \\
\hline \multicolumn{2}{|l|}{ Hunt \& Hess grade } \\
\hline V & $6(19.4)$ \\
\hline IV & $1(3.2)$ \\
\hline III & $4(12.9)$ \\
\hline II & $6(19.4)$ \\
\hline I & $14(45.2)$ \\
\hline \multicolumn{2}{|l|}{ Size of aneurysm in mm } \\
\hline Mean \pm SD & $15.8 \pm 7.9$ \\
\hline Range & $4-36$ \\
\hline Multiple aneurysms & $11(35.5)$ \\
\hline \multicolumn{2}{|l|}{ Aneurysm location } \\
\hline ICA: ophthalmic/superior hypophyseal & $12(38.7)$ \\
\hline ICA: PCoA/anterior choroidal & $6(19.4)$ \\
\hline ACoA & $5(16.1)$ \\
\hline Pericallosal & $1(3.2)$ \\
\hline Basilar & $4(12.9)$ \\
\hline PCoA & $2(6.4)$ \\
\hline PICA & $1(3.2)$ \\
\hline
\end{tabular}

$\mathrm{ACoA}=$ anterior communicating artery; $\mathrm{GCS}=$ Glasgow Coma Scale; $\mathrm{PCoA}=$ posterior communicating artery; PICA = posterior inferior cerebellar artery.

* Values are number of patients (\%) unless stated otherwise.

nor symptoms (mRS Score 1), 19.4\% of patients had slight disability (mRS Score 2), $16.1 \%$ of patients had moderate disability (mRS Score 3), and 3.2\% of patients had moderately severe disability (mRS Score 4). Of the 31 patients, 
TABLE 2. Perioperative coiling outcomes and complications

\begin{tabular}{|c|c|}
\hline Procedure Characteristics & Value* $^{*}$ \\
\hline No. of aneurysms/patients coiled & $31 / 31(100)$ \\
\hline \multicolumn{2}{|l|}{ Age at time of coiling in yrs } \\
\hline Mean \pm SD & $52.1 \pm 11.0$ \\
\hline Range & $30-72$ \\
\hline \multicolumn{2}{|l|}{ No. of coils used } \\
\hline Mean \pm SD & $5.7 \pm 2.8$ \\
\hline Range & $2-13$ \\
\hline Balloon assisted & $1 / 31(3.2)$ \\
\hline Stent assisted & 0 \\
\hline \multicolumn{2}{|l|}{ Intraop complications } \\
\hline Intraop rupture & $2 / 31(6.5)$ \\
\hline Intraop rupture morbidity/mortality & $0(0.0)$ \\
\hline Coil prolapse, flow limiting & $1 / 31(3.2)$ \\
\hline Coil prolapse, non-flow limiting & $2 / 31(6.5)$ \\
\hline Thrombus/embolus formation & $0(0.0)$ \\
\hline Parent artery occlusion/stenosis & $1 / 31(3.2)$ \\
\hline Intraop thrombolytic use & $1 / 31(3.2)$ \\
\hline Catheter-induced vasospasm & $1 / 31(3.2)$ \\
\hline Parent artery dissection & 0 \\
\hline Groin hematoma & $2 / 31(6.5)$ \\
\hline \multicolumn{2}{|l|}{ Periop complications } \\
\hline Hydrocephalus nonshunted & $1 / 31(3.2)$ \\
\hline Hydrocephalus transiently shunted & $14 / 31(45.2)$ \\
\hline Hydrocephalus permanently shunted & $6 / 31(19.4)$ \\
\hline Vasospasm medically treated & $9 / 31(29)$ \\
\hline Vasospasm endovascular treatment & $5 / 31(16.1)$ \\
\hline Transient neurological deficits & $11 / 31(35.5)$ \\
\hline Permanent neurological deficits & $6 / 31(19.4)$ \\
\hline Rebleeding & $1 / 31(3.2)$ \\
\hline \multicolumn{2}{|l|}{ Ischemic/thromboembolic stroke } \\
\hline Early ( $\leq 30$ days) & $4 / 29(13.8)$ \\
\hline Late (>30 days) & $0(0.0)$ \\
\hline Morbidity & $2 / 29(6.9)$ \\
\hline Mortality & $0(0.0)$ \\
\hline
\end{tabular}

* Values are number of patients (\%) unless stated otherwise.

there was 1 case of permanent morbidity related to carotid occlusion and vasospasm (mRS Score 5) that precluded further flow-diversion therapy. There were 3 cases of mortality due to complications of the original subarachnoid hemorrhage (9.7\%).

\section{Flow-Diversion Therapy Perioperative Outcomes}

Perioperative outcomes of flow-diversion therapy are summarized in Table 3. A total of 27 patients underwent staged placement of the flow diverter after adequate recovery from the prior subarachnoid hemorrhage (87.1\%). The Pipeline Embolization Device (PED) (Covidien/ev3 Neurovascular) was used in $77.7 \%$ of cases (21 patients), while the Flow Re-Direction Endoluminal Device (FRED, MicroVention, Inc.) and Silk devices (SFD; Balt Extrusion)
TABLE 3. Perioperative flow-diverter outcomes and complications

\begin{tabular}{|c|c|}
\hline Variable & Value $^{*}$ \\
\hline No. of aneurysms/patients w/ flow diversion & $27 / 31(87.1)$ \\
\hline \multicolumn{2}{|l|}{ Interval btwn coiling \& FD in wks } \\
\hline Mean \pm SD & $26.6 \pm 26.2$ \\
\hline Range & $1-100$ \\
\hline \multicolumn{2}{|l|}{ No. of FDs placed successfully } \\
\hline 1 & $26 / 27(96.3)$ \\
\hline 2 & $1 / 27(3.7)$ \\
\hline \multicolumn{2}{|l|}{ Technical complications/adjunctive techniques } \\
\hline Unsuccessful FD placement & $2 / 27(7.41)$ \\
\hline Removal of incompletely deployed FD & $1 / 27(3.7)$ \\
\hline Adjunctive microballoon & $1 / 27(3.7)$ \\
\hline Adjunctive coiling & $3 / 27(11.1)$ \\
\hline \multicolumn{2}{|l|}{ Intraop/periop complications } \\
\hline Intraop rupture & $0(0.0)$ \\
\hline Device migration & $0(0.0)$ \\
\hline Thrombus formation, flow limiting & $2 / 27(7.4)$ \\
\hline Parent artery occlusion/stenosis & 0 \\
\hline Branch occlusion/stenosis & $1 / 27(3.7)$ \\
\hline Distal emboli & $2 / 27(7.4)$ \\
\hline Intraoperative abciximab use & $2 / 27(7.4)$ \\
\hline Catheter-induced vasospasm & $0(0.0)$ \\
\hline Parent artery dissection & $0(0.0)$ \\
\hline Groin hematoma & $1 / 27(3.7)$ \\
\hline Transient neurological deficits & $3 / 27(11.1)$ \\
\hline Permanent neurological deficits & $2 / 27(7.4)$ \\
\hline \multicolumn{2}{|l|}{ Intraparenchymal hemorrhage complications } \\
\hline Early ( $\leq 30$ days) & $0(0.0)$ \\
\hline Late (>30 days) & $0(0.0)$ \\
\hline \multicolumn{2}{|l|}{ Ischemic/thromboembolic stroke complications } \\
\hline Early ( $\leq 30$ days) & $1 / 27(3.7)$ \\
\hline Late (>30 days) & $0(0.0)$ \\
\hline \multicolumn{2}{|l|}{ Perforator infarction complications } \\
\hline Early ( $\leq 30$ days) & $0(0.0)$ \\
\hline Late (>30 days) & $0(0.0)$ \\
\hline
\end{tabular}

were each used in $7.4 \%$ of cases (2 patients). The p64 (Phenox) and Derivo (Pforzheim) device were each used in 1 patient. A single flow-diversion device was placed in 26 cases. In 3 of these 26 cases, initial PED placement was initially unsuccessful but was successfully reattempted at a later date. Adjunctive coiling was performed in 2 aneurysms treated with the PED and in 1 aneurysm treated with the Silk device.

The median time between previous coiling and successful flow-diverter treatment was 17 weeks (range 8 days to 100 weeks). On preprocedural angiography, $92.6 \%$ of patients had aneurysms that were incompletely occluded, and $7.4 \%$ of patients had aneurysms that were nearly 
completely occluded with residual neck or dog-ear filling. At the time of the procedure, $51.9 \%$ of patients (14 cases) reported they had no symptoms, $22.2 \%$ of patients (6 cases) reported minor symptoms (mRS Score 1), 18.5\% of patients (5 cases) reported slight disability, 1 patient reported moderate disability, and 1 patient reported moderate severe disability.

Intraprocedural complications related to thrombus formation occurred in 2 patients (7.4\%). Intraoperative abciximab infusion was given in both cases and complete recanalization was achieved. No other patient experienced any intraprocedural complications including device migration, parent or branch vessel dissection, or vasospasm. During the perioperative phase, 3 patients (11.1\%) experienced minor complications with no permanent morbidity or mortality, including 2 transient ischemic attacks (6.4\%) and 1 groin hematoma (3.7\%). In the group of patients who underwent flow-diversion therapy, there were no other cases of ischemic/thromboembolic stroke, intraparenchymal hemorrhages, or perforator infarctions, and no cases of mortality or permanent morbidity.

\section{Clinical Outcomes}

Clinical outcomes at all stages of treatment are summarized in Table 4. All 27 patients who underwent flowdiversion therapy underwent clinical follow-up with a mean time of $18.3 \pm 12.3$ months (range $0-40$ months). Among patients who received flow-diverter therapy, at the time of discharge from flow-diversion placement, $48.1 \%$ (13 patients) of patients had no symptoms, 33.3\% (9 patients) of patients had absence of significant disability, $11.1 \%$ (2 patients) of patients slight disability, and 7.4\% (2 patients) of patients had moderate disability.

Among all patients at last follow-up, analyzed on an intent-to-treat basis, $45.2 \%$ (14 cases) of patients reported no symptoms, $22.6 \%$ (7 cases) of patients reported absence of significant disability, $12.9 \%$ (4 cases) of patients reported slight disability, 1 patient (3.2\%) reported moderate disability, 1 patient $(3.2 \%)$ reported moderate severe disability, 1 patient had severe disability, and 3 patients (9.7\%) died.

\section{Angiographic Outcomes}

Angiographic outcomes at all stages are summarized in Table 5. At the time of flow-diverter treatment, $92.6 \%$ and $7.4 \%$ of patients who went on to staged Pipeline embolization had incomplete and near-complete occlusion of the aneurysmal sac at the time of flow diversion, respectively.

Of the 31 patients who were initially included in this study, 24 patients underwent radiological follow-up and 7 did not (1 patient refused further imaging studies, 1 patient was lost to follow-up, 1 patient has not yet reached the date for first follow-up imaging, 3 patients died, and 1 patient suffered severe disability). The mean time of last radiological follow-up was $19.2 \pm 12.0$ months (range 1-40 months). The imaging modality at the last follow-up study was digital subtraction angiography in 14 patients, MR angiography in 10 patients, and CT angiography in 1 patient. At the time of the last imaging study, 15 patients (48.4\% on intent-to-treat basis) had aneurysms that were com-
TABLE 4. Neurological outcomes

\begin{tabular}{ccccc}
\hline & \multicolumn{4}{c}{ No. of Patients (\%) } \\
\cline { 2 - 5 } $\begin{array}{c}\text { mRS } \\
\text { Score }\end{array}$ & $\begin{array}{c}\text { Score at } \\
\text { Discharge from } \\
\text { Coiling }\end{array}$ & $\begin{array}{c}\text { Score at } \\
\text { Time of } \\
\text { FD* }^{*}\end{array}$ & $\begin{array}{c}\text { Score at } \\
\text { Discharge } \\
\text { from FD* }\end{array}$ & $\begin{array}{c}\text { Score at Last } \\
\text { Follow-Up† }\end{array}$ \\
\hline 0 & $10(32.3)$ & $14(51.9)$ & $13(48.1)$ & $14(45.2)$ \\
\hline 1 & $5(16.1)$ & $6(22.2)$ & $9(33.3)$ & $7(22.6)$ \\
\hline 2 & $6(19.4)$ & $5(18.5)$ & $2(11.1)$ & $4(12.9)$ \\
\hline 3 & $5(16.1)$ & $1(3.7)$ & $2(7.4)$ & $1(3.2)$ \\
\hline 4 & $1(3.2)$ & $1(3.7)$ & $1(3.7)$ & $1(3.2)$ \\
\hline 5 & $1(3.2)$ & $0(0.0)$ & $0(0.0)$ & $1(3.2)$ \\
\hline 6 & $3(9.7)$ & $0(0.0)$ & $0(0.0)$ & $3(9.7)$ \\
\hline
\end{tabular}

* Results reported only for patients receiving flow-diverter treatment.

$\dagger$ Results reported on an intention-to-treat basis.

pletely occluded, 3 patients (9.7\% on intent-to-treat basis) had aneurysms that were nearly completely occluded, and 4 patients (12.9\% on intent-to-treat basis) remained with a stable but incompletely occluded aneurysm.

There was 1 case of retreatment/additional PED treatment. This patient underwent treatment of a basilar bifurcation aneurysm with the PED. However, the patient required retreatment at 40 weeks after initial PED treatment due to progressive filling of the residual aneurysm with increase in size, mild hydrocephalus and mass effect on the brainstem. This case is demonstrated in Fig. 1.

\section{Discussion}

Our study demonstrated that staged planned coiled embolization in the setting of acute SAH followed by flow-diverter treatment after recovery from the SAH is both safe and effective. We found that this strategy is valuable for complex ruptured aneurysms as it allows for transitioning of the patient from the acute phase where dual antiplatelet therapy would be contraindicated to a more subacute phase where the patient and aneurysm are stabilized and dual antiplatelet therapy is safer. Importantly, we observed only 1 case of rebleeding, suggesting that partial coiling in the acute phase is feasible. Complications were mostly observed during the period immediately following the SAH and were related to the coiling procedure or the SAH itself.

Other studies reported the use of flow diversion for treatment of acutely ruptured aneurysms. Chalouhi et al. reported a series of 20 patients with ruptured aneurysms treated with the PED in the acute phase. Of these, 4 patients had staged coiling followed by PED treatment and 6 patients had adjunctive coiling during PED treatment. Over $90 \%$ of patients had good neurological and angiographic outcomes in this study. ${ }^{2}$ McAuliffe et al. reported a series of 11 acutely ruptured aneurysms treated with the PED within 1 month of rupture. Of these aneurysms, 6 received concomitant coiling. Two aneurysms treated with the PED alone reruptured in the acute phase, leading to death in both cases. ${ }^{9}$ Similar to our strategy, Nossek et al. reported the use of staged coiling followed by PED treatment of 2 ruptured aneurysms with good results. ${ }^{11}$ However, to our knowledge our study is the first report to 
TABLE 5. Angiographic outcomes

\begin{tabular}{lccc}
\hline & \multicolumn{3}{c}{ No. of Patients (\%) } \\
\cline { 2 - 4 } $\begin{array}{c}\text { Angiographic } \\
\text { Occlusion }\end{array}$ & $\begin{array}{c}\text { Immediate } \\
\text { Postcoiling } \\
\text { Angiogram }\end{array}$ & $\begin{array}{c}\text { Pre-Flow } \\
\text { Diversion } \\
\text { Angiogram* }\end{array}$ & $\begin{array}{c}\text { Occlusion at } \\
\text { Last } \\
\text { Follow-Up† }\end{array}$ \\
\hline Complete & $3(9.7)$ & $0(0.0)$ & $15(48.4)$ \\
\hline Near complete & $13(41.9)$ & $2(7.4)$ & $3(9.7)$ \\
\hline Incomplete & $14(48.4)$ & $25(92.6)$ & $4(12.9)$ \\
\hline
\end{tabular}

* Analysis on non-intent-to-treat basis.

$\dagger$ Analysis on intent-to-treat basis.

provide an in-depth analysis of complications, rebleeding rates, and long-term efficacy in a consecutive series where the goal was immediate protection from rebleeding with coils while allowing patients to recover from the acute effects of the SAH, thus allowing for safer delayed use of flow diverters. In our study of large and complex ruptured aneurysms, good neurological and angiographic outcomes were achieved in approximately $80 \%$ and $60 \%$ of patients, respectively. We consider this a remarkable achievement given the complexity of some of the aneurysms treated and the fact that $23 \%$ of patients had presented with poor-grade SAH.

There are a number of important factors to consider when deciding to pursue the treatment strategy outlined in this report. The ultra-early treatment of ruptured aneurysms with endovascular coiling is increasingly well established; however, the idea of not attempting complete obliteration of the aneurysm during the initial treatment remains largely unexamined. . $^{3,8,13,14}$ In our experience, it is important that the goal of this combined approach is to achieve just enough packing density to prevent early rebleeding but is not so aggressive so as to perforate the aneurysm or tightly pack the aneurysm, risking coil prolapse. The risks of such aggressive treatment are demonstrated in our patient who suffered an ICA occlusion, which was most likely related to overpacking of the aneurysm, which compromised the parent artery. While our study demonstrated only 1 case of rebleeding despite high rates of incomplete occlusion during the initial treatment, the risks of incompletely packing a ruptured aneurysm are well established. The Cerebral Aneurysm Rerupture After Treatment (CARAT) study demonstrated a rerupture rate of $3.4 \%$ for coiled ruptured aneurysms with a median time to rerupture of 3 days. The degree of aneurysm occlusion was the strongest predictor of rerupture with rupture rates of $17.6 \%$ of aneurysms that were less than $70 \%$ occluded. ${ }^{5}$ Sluzewski et al. found that incomplete initial aneurysm occlusion was associated with higher odds of early rerupture for coiled ruptured intracranial aneurysms. ${ }^{12}$ Jartti et al. found an early rebleeding rate of $8.8 \%$ among incompletely coiled
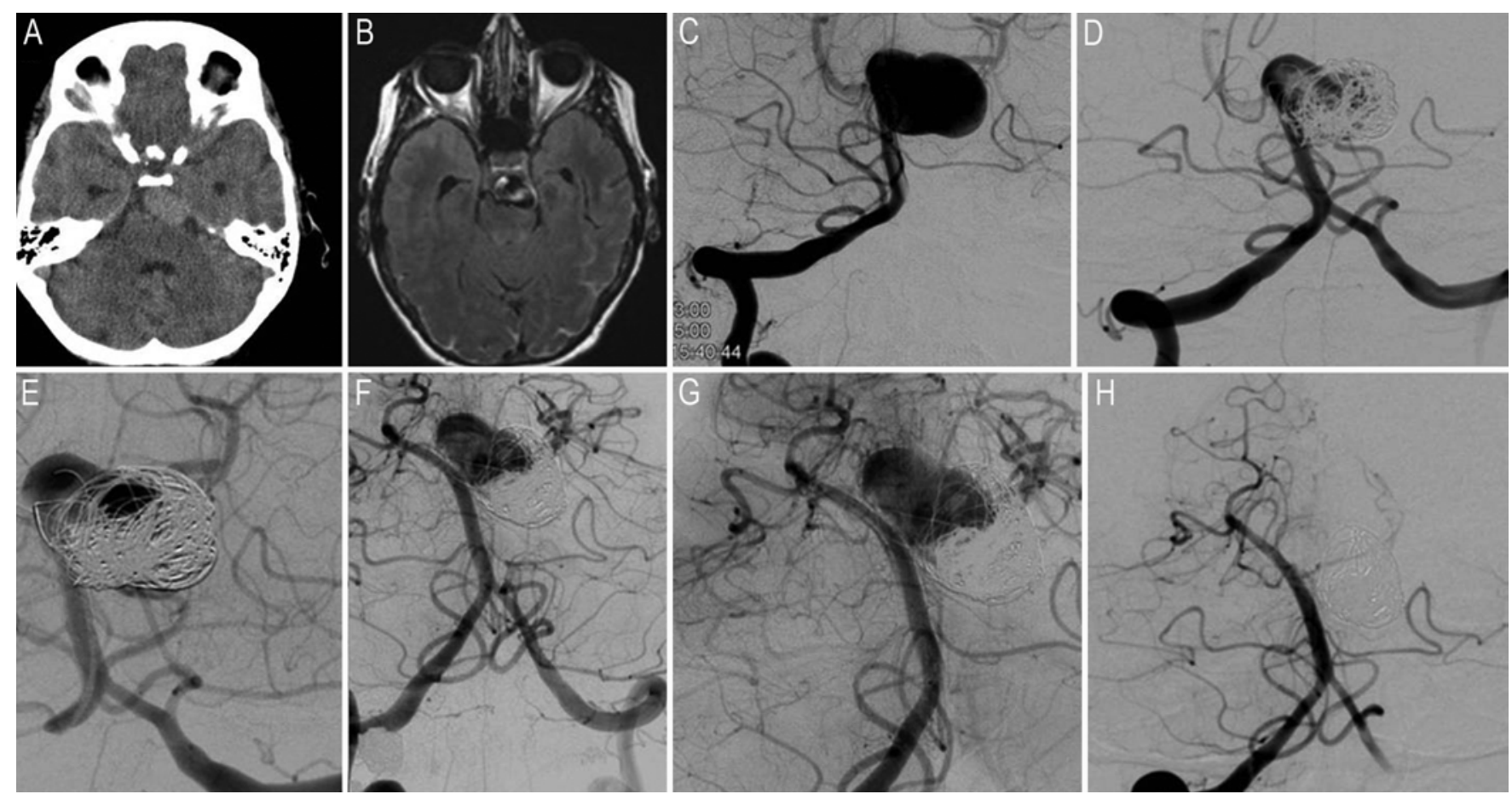

FIG. 1. Case example. A 68-year-old female patient with a family history of intracranial aneurysms presented with an increasingly intense headache and no focal neurological deficit. A: Head CT scan demonstrating a 2.2-cm mass in the prepontine cistern concerning for aneurysm with no CT evidence of subarachnoid hemorrhage. B: FLAIR MR image demonstrating increased signal in the subarachnoid space consistent with subarachnoid hemorrhage. C: Cerebral angiogram demonstrating a 2.2-cm basilar tip aneurysm incorporating both PCA branches. D: Following coil embolization, the aneurysm was partially occluded. E: The patient underwent staged treatment with the PED 18 days later. F: At 9 months of follow-up there was increasing filling of the aneurysm. The patient underwent placement of a second PED across the aneurysm neck. G: Follow-up angiogram obtained 30 months later, demonstrating complete obliteration of the aneurysm. 
ruptured aneurysms compared with $2.0 \%$ for aneurysms with a neck remnant. ${ }^{4}$ In using this strategy of incomplete coiling followed by delayed flow diversion, we have paid special attention to identifying the most likely point of rupture and targeted coiling with special emphasis in packing and thus protecting the rupture site while avoiding-when too risky-overpacking the neck to avoid compromise of the parent artery. However, based on the historically high rates of aneurysm recurrence following coiling of the types of lesions that were included in this study (i.e., large and/or complex aneurysms), we felt that postcoiling parent vessel reconstruction with flow diverters would offer the patients the best chance of an angiographic cure without the risks of surgery or aggressive endovascular coiling.

Another important factor to consider when choosing this treatment strategy is patient selection. When using this strategy, one has to keep in mind that patient compliance with dual antiplatelet therapy and imaging follow-up is key. This is illustrated in our case in Fig. 1 with a basilar bifurcation aneurysm in whom complete occlusion occurred over several months requiring close imaging and clinical follow-up, additional PED treatment, and careful modulation of antiplatelet drugs. We would not recommend this strategy in a potentially noncompliant patient who may not return for follow-up visits. Also, the safety and efficacy of flow diversion for non-ICA sidewall morphology is not well established ${ }^{6}$ and requires close scrutiny in larger numbers of patients. Importantly, in our study we did not perform routine platelet testing prior to flow-diverter treatment. There currently exists no evidence that preoperative platelet testing results in improved outcomes among patients receiving flow-diverter therapy with the PED. In fact, in a recently performed subgroup analysis of the International Retrospective Study of Pipeline Embolization Device registry, the use of platelet testing was associated with higher odds of morbidity and mortality. ${ }^{1}$

Our study has limitations. While patients included in this study were part of a prospectively collected database, we did not establish an a priori study protocol; thus, there were no strict criteria regarding important factors such as antiplatelet therapy regimens. In the setting of complex aneurysms such as those treated in our study, it is difficult to establish a set protocol as each aneurysm is unique and treatment decisions need to be made on a case-by-case basis. All angiographic outcomes were assessed by the operator and not by an independent core laboratory, which could increase the risk of bias. In addition, 7 patients did not undergo any follow-up imaging. Due to the lack of complete follow-up, we analyzed our final angiographic outcomes on an intent-to-treat basis. Clinical outcomes were based on patient self-assessment in one center while they were assessed by a member of the treatment team in the other. Lastly, the significance of aneurysm remnants after flow diversion is not well understood as very few studies exist following flow-diverter patients beyond 1-2 years posttreatment. Using very strict criteria of angiographic complete occlusion, our complete occlusion rate was only $48.4 \%$, although most of the residual filling was minimal considering the complexity of these aneurysms and of questionable clinical significance. Lastly, we did not include a control group in this study. Therefore, it is difficult to determine if our treatment strategy would be superior to a treatment strategy that involved either coiling with intent to completely occlude the aneurysm or surgical clipping.

\section{Conclusions}

Staged treatment of ruptured intracranial aneurysms with coiling in the acute phase and flow-diverter treatment following recovery from SAH is both safe and effective. In our series, all major morbidity and mortality occurred during the acute rupture phase. One case of rebleeding occurred during the interval between coiling and flow diversion. No patients suffered additional morbidity or mortality from flow-diverter treatment. Further studies with robust longitudinal follow-up are needed to determine if this is an ideal treatment strategy for complex ruptured intracranial aneurysms.

\section{References}

1. Brinjikji W, Lanzino G, Cloft HJ, Siddiqui AH, Hanel RA, Kallmes DF: Platelet testing is associated with worse clinical outcomes for patients treated with the Pipeline embolization device. AJNR Am J Neuroradiol [epub ahead of print], 2015

2. Chalouhi N, Zanaty M, Whiting A, Tjoumakaris S, Hasan $\mathrm{D}$, Ajiboye N, et al: Treatment of ruptured intracranial aneurysms with the pipeline embolization device. Neurosurgery 76:165-172, 2015

3. Gu DQ, Zhang X, Luo B, Long XA, Duan CZ: Impact of ultra-early coiling on clinical outcome after aneurysmal subarachnoid hemorrhage in elderly patients. Acad Radiol 19:3-7, 2012

4. Jartti P, Isokangas JM, Karttunen A, Jartti A, Haapea M, Koskelainen T, et al: Early rebleeding after coiling of ruptured intracranial aneurysms. Acta Radiol 51:1043-1049, 2010

5. Johnston SC, Dowd CF, Higashida RT, Lawton MT, Duckwiler GR, Gress DR: Predictors of rehemorrhage after treatment of ruptured intracranial aneurysms: the Cerebral Aneurysm Rerupture After Treatment (CARAT) study. Stroke 39:120-125, 2008

6. Kallmes DF, Hanel R, Lopes D, Boccardi E, Bonafé A, Cekirge S, et al: International retrospective study of the pipeline embolization device: a multicenter aneurysm treatment study. AJNR Am J Neuroradiol 36:108-115, 2015

7. Leake CB, Brinjikji W, Kallmes DF, Cloft HJ: Increasing treatment of ruptured cerebral aneurysms at high-volume centers in the United States. J Neurosurg 115:1179-1183, 2011

8. Luo YC, Shen CS, Mao JL, Liang CY, Zhang Q, He ZJ: Ultra-early versus delayed coil treatment for ruptured poorgrade aneurysm. Neuroradiology 57:205-210, 2015

9. McAuliffe W, Wenderoth JD: Immediate and midterm results following treatment of recently ruptured intracranial aneurysms with the Pipeline embolization device. AJNR Am J Neuroradiol 33:487-493, 2012

10. Molyneux A, Kerr R, Stratton I, Sandercock P, Clarke M, Shrimpton J, et al: International Subarachnoid Aneurysm Trial (ISAT) of neurosurgical clipping versus endovascular coiling in 2143 patients with ruptured intracranial aneurysms: a randomised trial. Lancet 360:1267-1274, 2002

11. Nossek E, Chalif DJ, Chakraborty S, Lombardo K, Black KS, Setton A: Concurrent use of the Pipeline Embolization Device and coils for intracranial aneurysms: technique, safety, and efficacy. J Neurosurg 122:904-911, 2015

12. Sluzewski M, van Rooij WJ, Beute GN, Nijssen PC: Late rebleeding of ruptured intracranial aneurysms treated with detachable coils. AJNR Am J Neuroradiol 26:2542-2549, 2005 
13. van Loon J, Waerzeggers Y, Wilms G, Van Calenbergh F, Goffin J, Plets C: Early endovascular treatment of ruptured cerebral aneurysms in patients in very poor neurological condition. Neurosurgery 50:457-465, 2002

14. Wong GK, Boet R, Ng SC, Chan M, Gin T, Zee B, et al: Ultra-early (within 24 hours) aneurysm treatment after subarachnoid hemorrhage. World Neurosurg 77:311-315, 2012

\section{Disclosures}

The authors report the following. Dr. Kallmes: support of nonstudy-related clinical or research effort from eV3/Covidien, MicroVention, NeuroSigma, Codman, Sequent, and Sumodics. Dr. Boccardi: consultant for Covidien and Microvention. Dr. Lanzino: consultant for Covidien.

\section{Author Contributions}

Conception and design: Lanzino, Brinjikji, Fang, Pero, Boccardi Acquisition of data: Lanzino, Brinjikji, Piano, Fang, Pero, Quilici, Valvassori, Lozupone, Cloft. Analysis and interpretation of data: Lanzino, Brinjikji, Piano, Fang, Quilici, Valvassori, Lozupone, Boccardi. Drafting the article: Lanzino, Brinjikji, Piano, Fang, Lozupone, Cloft. Critically revising the article: Lanzino, Brinjikji, Fang, Pero, Quilici, Valvassori, Cloft, Boccardi. Reviewed submitted version of manuscript: Lanzino, Brinjikji, Piano, Fang, Pero, Quilici, Valvassori, Cloft, Boccardi. Statistical analysis: Lanzino, Brinjikji, Fang. Administrative/technical/material support: Lanzino, Brinjikji, Piano, Fang, Pero, Valvassori, Cloft, Boccardi. Study supervision: Lanzino, Piano, Cloft.

\section{Correspondence}

Giuseppe Lanzino, Department of Neurological Surgery, Mayo Clinic, 200 First St. SW, Rochester MN 55905. email: lanzino. giuseppe@mayo.edu. 